\section{THE STYLISTIC AND ICONOGRAPHIC CONSIDERATION OF AWHA NDIAGU POTTERY AND THE IGBO AESTHETIC EVALUATION}

\section{Emman N. Okunna}

\section{Abstract}

Among the Igbo, the artist is recognized for the skill which he possesses, the skill which the Igbo refer to as $n k a$. This possession is admired among the people, and comes in strongly into the aesthetic admiration of the works of the artist. Among the Awha-Ndiagu potters, this aesthetic admiration is ventilated in the surface ornamentation of their pottery. This paper examines the stylistic and iconographic content of the pottery of this community against the backdrop of the possible classification of their pottery into two broad groups: forms for ceremonials and festivals, and forms for everyday use. It concludes that these stylistic and iconographic contents and statements therefore fit into the differing principles of Igbo aesthetic evaluation.

\section{Introduction}

The discovery of the art of pottery was crucial to the development of the early man as he needed cooking and storage containers (Nelson, 1966). It is therefore not difficult to understand why the wide distribution of pottery the world over. Its development dates back to the early civilization made possible by man's inevitable and unavoidable closeness to and contact with the earth.

In the contemporary Nigerian art experience, pottery occupies a very visible position. It is reckoned with among the various creative activities that have engaged traditional artists in various communities across the country. Among the Igbo are several of such communities, one of which strong ones is Awha-Ndiagu, a community in the present Ezeagu Local Government Area of Enugu State. According
Emman N. Okunna

to Umunna (2005), it is about fifty five kilometers south-west of Enugu and situates along the popular $9^{\text {th }}$ Mile Corner to Nsukka road. It has a very rugged and an undulating terrain. But remarkably it is blessed with an abundance of clay, a situation that echoes Yanagi's (1978), assertion that "no handicraft has arisen where no good natural material exists."

Historically, the lack of information about the development of this traditional industry is very intense. No one of the potters can trace the development of the art of pottery in the community. According to Nwokike (2005), the potters believe they were born into it. This situation can easily be supplanted for other Igbo pottery communities, as they are largely the same. For example, writing about the art of pottery in Inyi, Ikenegbu (1981), says, "No living potter in the town has been able to trace the origin of pottery in their community." According to him, most of the potters had claimed that the art of making pottery was inherent in them. The situation as enunciated notwithstanding, their pottery is marked out by their technical and aesthetic content. Awha Ndiagu potters demonstrate in these works a high sense of judgment which echoes the great dexterity and craftsmanship displayed in their pottery forms. The degree of accuracy and the high sense of precision these potters have built up over time in their pottery practice are unmistakable. Their stylistic approach is largely dictated by the nature of their material - clay. The delicate nature of this medium at every stage of its consistency, be it soft, leather-hard, bone dry or fired, demands a large measure of caution in its handling. The plasticity of the clay has enabled the high sense of symmetry the potters have displayed in their works. This symmetry first ensures that these pots sit well, without any fear of tripping apart from the mathematical judgment displayed in them.

Perhaps, too, the same nature of the medium of production has also informed the avoidance of any form of abstraction by 
these potters. Their forms, varied as they are, are generally well bellied, a character which further enhances the stability of their forms. It is strongly evident in their production, whether the pots are of the big or large sizes, small or medium.

It is pertinent to note here that while basically all pottery forms are spherical or rounded in shape, some of the Awha Ndiagu pottery forms (Figs. $1 \& 2$ ) echo the deep mathematical sense already referred to these potters have brought to bear in their works. The forms they have designed with wide and thick rims they have also given had very short neck. These formalistic characters have given these forms very sturdy structure. The forms they designed with narrow mouths, they finished also with either short or long slim neck with the rim flared. But in all these instances the pots are adequately bellied too to ensure their stability. However, being the creative minds they are, these potters have in a few instances ventured out into the world of abstraction. The potters have strongly demonstrated this sense of adventurism in such forms as Chi Okpa Naa (Fig. 3) and Ite Ekwu Alio (Fig. 4). Formalistically the Chi Okpa Naa is mushroomic, with heavily flaring top on a delicately slim stem, while the Ite Ekwu Alio has the form of an alluring nut or fruit with the base tailing to a fine point. The neck is short while the rim is little flared. But what these pottery forms may have lost in stability by the seeming adventurism of these potters, they have made up in other ways. For example, the Ite Ekwu Alio is usually rested on its rim when not in use. But when in use it is stood on a soft pad made from banana leaves. On the other hand, the Chi Okpa Naa is usually stood upright by burying a little length of its stem in the ground, and when not in use, rested on its side.

\section{Iconographic Content}

Iconographically, Awha-Ndiagu pottery stand out prominently too, as they echo the high sense of ornamentation of the potters to enhance the aesthetic quality of the forms. This phenomenon eloquently demonstrates that aesthetics is an intrinsic and extrinsic part of Igbo pottery. But this was unfortunately played down for a very long time because early writers on African art had concentrated only on the theme of religious orientation. (Aniakor, 1982). For these writers African art was merely an image of divinity, a situation he argues, was easy to understand, as early writings on the visual arts were done largely by social - anthropologists.

It was perhaps because of this that the general tendency according to d'Azevedo (1974), was to view African art objects from the Western world's "lifelong indoctrination by culture with the idea that art is an echo of divinity." But later studies share in common the observation that in traditional Africa, works of art were not only evaluated but also verbalized. Aniakor (1982) further stresses that "there was and is in existence a large stock of aesthetic vocabularies from which evaluators can readily draw upon when commenting on art objects." On the other hand Cordwell (1959) notes that "The vocabulary regarding what is beautiful encompasses such factors as wealth, prestige, status and political symbolism."

\section{Igbo Aesthetic Merit}

To talk of beauty among the Igbo immediately brings to mind the word mma which the people use very widely to refer to any and everything the Igbo consider as being beautiful. But of immense importance in the consideration is the extent to which the skill of the artist is made manifest subject to such other factors as social and economic status of the patron. When a man commissions a work of art he already anticipates the creative standard of work to be produced relative to his status, both social and economic, and that of the artist himself - a phenomenon that is true of the Awha Ndiagu pottery associated with ceremonies.

As Aniakor (1982), notes "that the Igbo attribute a high degree 
of aesthetic merit to art objects relative to their structural complexity is also true of Igbo pottery." This assertion is very true of the ceremonial pottery forms of this community. The difference resides in the fact that in pottery forms, one deals with basic shape that do not permit the building up of many forms in space as in sculpture, a situation that is traceable to "the functions of pottery or more especially in the nature of the clay material used." Therefore, in pottery, the accent is on the use of decorative patterns and symbols so that, the structural complexity of sculpture is here replaced by decorative complexity. (Aniakor 1982).

The pottery types of everyday use among the Awha Ndiagu are either for cooking, for eating, or for water storage. These pottery types do not usually bear any decorations (Figs. 1, 2) on them and therefore could be described as 'cold'. But their aesthetic quality resides in their utility, a phenomenon validated by Yanagi's (1978), assertion that "the beauty of pottery finds its fullest expression only when it is joined to utility." He argues that modern artist potters forget that the main aim of handicrafts is primarily concerned with utility, not ornament, adding that they apparently believe that nothing can possess nobility or dignity if made for common use. And he goes on: "they forget that all the best of the old pieces which we value so highly today were made not for ornament but for the ordinary purposes of the household."

Perhaps no other summarises the aesthetic admiration of the Awha Ndiagu pottery more evocatively than Aniakor's (1982), description of Igbo pottery in what he refers to as "market aesthetics":

One context for understanding aspects of Igbo pottery aesthetics is in the market, especially when a buyer and seller are negotiating the price of a pot. Some of the aesthetic gestures of the buyer are noteworthy. First, she takes up the pot and feels the weight in both hands. Weight is important because it tells something of the strength of the pot, a factor that brings function into the aesthetic package. Second, she now taps the pot in order to hear its sound or more appropriately echo from the interior. Sound is an aspect of the aesthetic quality of a pot. It helps to indicate if the pot was well fired and if it has an internal damage like a hidden crack resulting from bad firing. Third, she runs her hand inside the pot interior in order to fell the smoothness of the walls, a factor that reveals the level of artistry shown in the fabrication of the pottery piece. Fourth, she feels the neck areas of the pot in order to ascertain its relative strength, thus establishing the overall functional strength of the pot. Finally, the pot is held in both hands, thrown gently into the air a few inches above the palms to which it returns gently. In doing these, the buyer is testing the overall quality of the pottery piece from the point of view of craftsmanship, strength and finish.

It is therefore unmistakable, going by the above, that domestic pottery pieces are bought and integrated into the domestic environment entirely not because of any surface embellishment. In most cases the pottery have no decorations whatsoever. But they are considered beautiful because of their overall functional strength, what Nwoko (1976), would refer to as "aesthetic functionalism."

On the other hand, Awha-Ndiagu potters demonstrate some high principles of aesthetic valuations in their pottery associated with ceremonies. The Ogbalu Igbo ghalii (fig 5), for example, is one of the most aesthetically unique pottery types among the people. It is unique for its enormous size and for its surface embellishment, usually embossed, drawing most of their aesthetic referents from plant and animal life. These iconographic symbols have been used rather elaborately not just because of the aesthetic response from 
admirers but also for their symbolism. Such animal motifs as the bull, lion and the crocodile, feature strongly, and symbolize strength. The symbol of the human hand feature strongly too - an eloquent statement about Igbo belief: aka aja aja, na ebute onu mmanu $m m a n u$, literally meaning: hard work begets enjoyment. The ropelike patterns the Igbo refer to as eriri ibe nne represent the Igbo man's strong link to his maternal home, affirming an Igbo saying: "when a man runs for his dear life he heads for his maternal home". It is pertinent to note here that Ogbalu Igbo ghalii of Awha-Ndiagu compares very strongly with Ite Ike of Inyi both formalistically and iconographically in their surface embellishment, although no link has yet been established between these two communities. It is therefore invariable that these pottery making communities have developed independently, but mindful of Igbo aesthetic valuation of their production.

Mballa, another ceremonial pottery which usually feature at marriages in the community, can easily be identified by their characteristically long and narrow neck and a flared rim. It is also unique for its surface embellishment, done in embossed patterns. While the iconographic referents have not derived from animal life, plant life, and the firmament have largely provided the Awha-Ndiagu potter with ready motifs. The eriri ibe nne which features in the surface embellishment of some other ceremonial pottery forms are readily and strongly evident in the surface adornment of the Mballa. The delicate lines formed by the head of kolanut, known by the Igbo as Isi Oji are not wanting here too. The use of this traditional motif in the ornamentation of the Mballa echo the importance of Oji, Kolanut, among the Igbo. Apart from their being beautiful to look at, used as design motifs on pottery by the potters in the community, Cole and Aniakor (1984) say of kolanut among the Igbo: "hospitality ceremonies centre upon sharing kolanut and/or white chalk, Nzu, both sacred substances used to bless any and every undertaking and to promote its success. It is difficult to imagine Igbo life without them." The circles embossed on the shoulder of this pottery form, represent the moon which symbolizes continuity. The top of the mushroomic head of the Chi Okpa Naa is loudly textured with cross-hatching patterns enclosed within two incised concentric circles. These cross-hatching patterns have further been divided into four roughly equal patterns representing the four market days in the traditional Igbo calendar: Oye, Afor, Nkwo and Eke. It is significant that the orifice which runs through the stem of this pottery piece is located at the point where the dividing lines meet, symbolizing a strong link, echoing brotherhood among the Igbo: onye aghana nwanne ya.

And so it is that the surfaces of these pottery forms that feature at ceremonies provide the Awha-Ndiagu potter the canvas on which to make statements about things of importance to the Igbo while at the same time enhancing the aesthetic quality of these pottery forms. The structural complexity usually associated with sculpture as Aniakor (1982) had noted is here in pottery strongly made manifest as decorative complexity. It is in this decorative complexity that the Igbo pottery is most eloquent in its visual expression. The fact is therefore unmistakable that the Igbo demonstrate high principles of aesthetic valuations in their pottery associated with ritual, ceremonies and leadership as strongly ventilated in the foregoing examples. The Igbo thus affirm a study edited by Fraser and Cole (1972) which has shown that most art objects associated with leadership in African societies are invariably more complex in forms and ornamentation. And so what informs this situation? Aniakor (1982), provides answers to this question. In his examination of art associated with leadership in African societies, he believes that:

Leaders, whether they are individuals or a group of persons such as cult leaders or men in a village council, 
enjoy the highest degree of social visibility because of their political influence, which is sustained through the use of exquisite works of art.

He adds that "the economic prosperity of the leader enables him to commission and own art objects whose range, quantity and types as well as quality are utilized to exert his social and political influence and authority." Awha-Ndiagu pottery in this category are not found wanting. They have become the external symbol of authority. Works of art are expressions of an artists inner feelings. But, these expressions do not proceed independently from the artist, exclusive of the society. They are therefore records or interpretations of values and experiences of the society of which the artists is a member. He is recognized by the society for the skill which he possesses, the skill which the Igbo refer to as nka. This possession is admired strongly among the people, a possession which comes in strongly into the aesthetic admiration of the works of the artist, ventilated in pottery, in the surface ornamentation of their forms. It is therefore understandable when such pottery forms as ite owoko, udu egwu among others that do not bear surface decorations are described as 'cold' inspite of their formalistic elegance. Or such other forms as Nshi described as light because of the numerous perforations on them.

\section{Conclusion}

The stylistic and iconographic statements made by the Awha Ndiagu pottery are unmistakably strong and clear. These statements which fit perfectly into the differing principles of Igbo aesthetic evaluation, situate in the different forms the potters produce - forms for ceremonials and festivals and forms for ordinary everyday use. When therefore beauty is verbalized among the Igbo, consideration may differ, hinged on the point of interest. Ite a mara mma could therefore refer to the joy which the effectiveness in use of a pottery form brings to the user, or the surface embellishment of a pottery form. Awha Ndiagu pottery, seen in their ceremonial forms, have their formal complexity in their surface adornment, which is an Igbo aesthetic referent. It is therefore easy to hear such phrasing as Aniakor (1982) notes: olua di egwu, when in the eyes of the Igbo a work of art literally instills in one fear, mixed with wonder. He notes that in more recent phrasing, the artist is said to have beaten the drum with great skill in a highly accomplished work of art: nwokea etie igba ebea. In effect musical expressions and terms are usefully employed in the aesthetic evaluation of the plastic arts - one of which strong components is pottery. Awha Ndiagu pottery therefore projects the cultural reality of the Igbo, the eyes of which it is and whose material culture it creates.

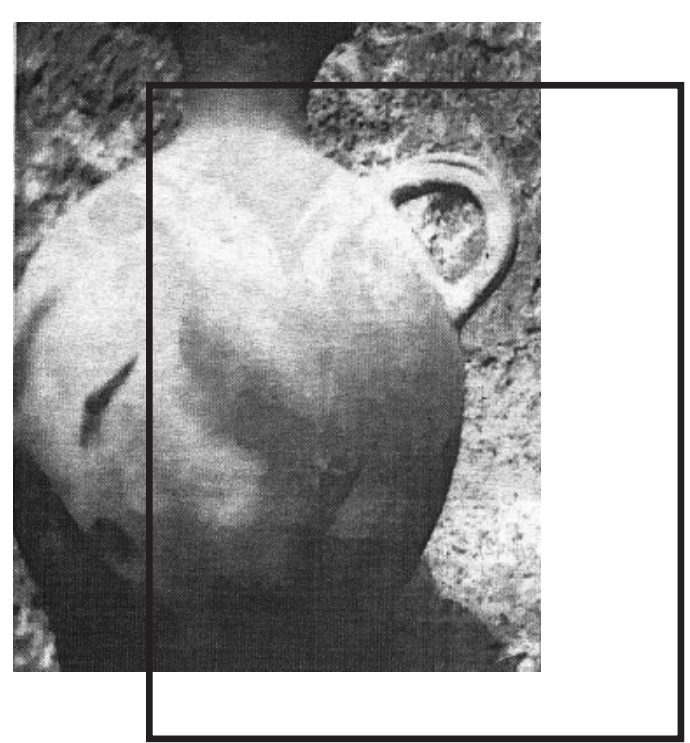

Fig 1: Ite mmiri

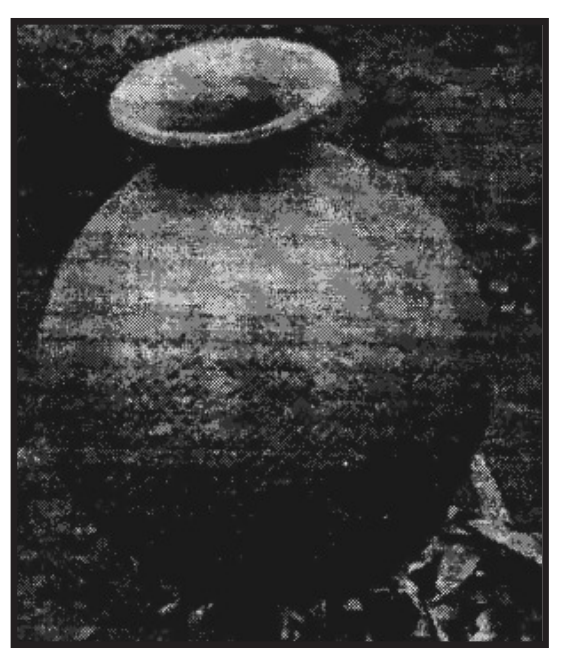

Fig 2: Another Ite mmiri 


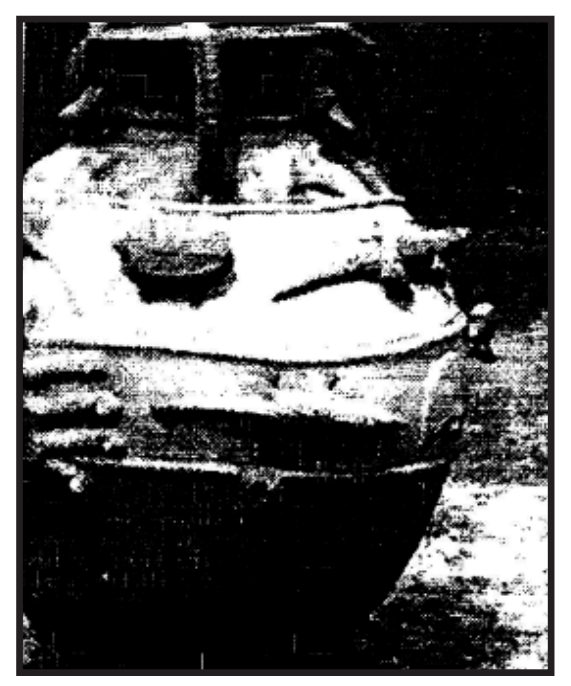

Fig 3: Ite Ekwu Alio

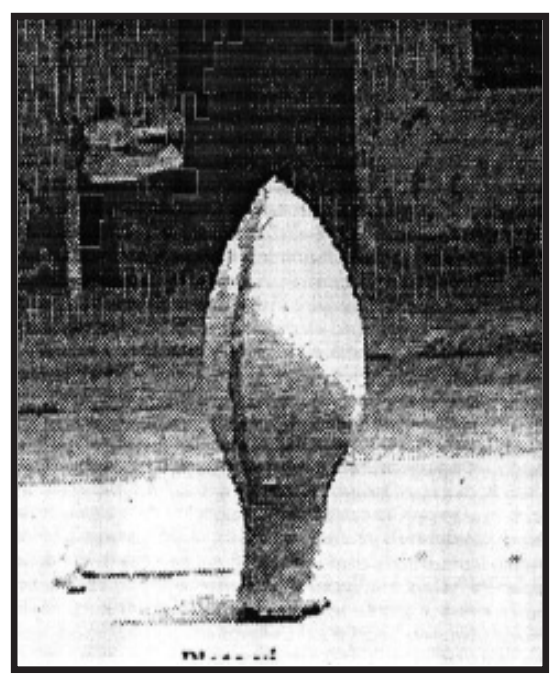

Fig 4: Ogbalu Igbo Ghalii

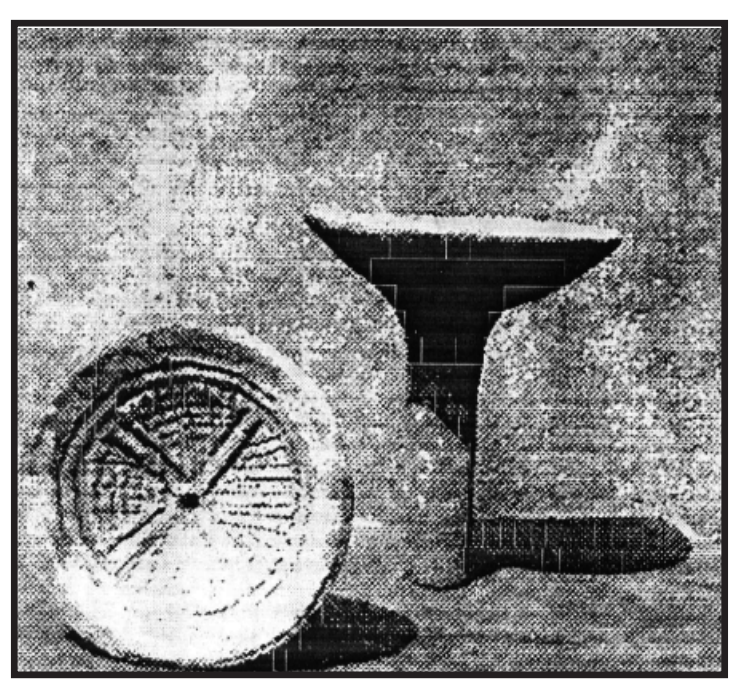

Fig 5: Chi Okpa Naa

* All the figures culled from J. Nwokike, 2005

\section{References}

Aniakor, C. C. (1982). Igbo aesthetics (An introduction). Nigeria Magazine. Lagos: Department of Culture, Federal Ministry of Youth and Culture. No. 141.

Cole, H., and Aniakor, C. C. (1984). Igbo arts: Community and cosmos. Los Angeles: University of California.

Cordwell, J. (1959). African art. Continuity and change in African Cultures. (ed. W. Bascom and M. Herskovits), Chicago: University of Chicago Press.

d'Azevedo, W. (1974). The traditional artist in African societies. Bloomington: University Press.

Ikenegbu, O. (1981). Pottery making in Inyi. An unpublished NCE project report, Awka: Anambra State College of Education.

Nelson, G. (1966). Ceramics: A potter's handbook. New York: Holt, Rinehart and Norton.

Nwokike, J. (2005). Pottery and cultural life of Awha people. Enugu: $\mathrm{M}$ 'Cal Comm. International.

Nwoko, D. (1976). The aesthetics of art in technology. Paper presented at the symposium on Contemporary Nigerian Art. Nsukka.

Umunna, A. (2006). Awha-Ndiagu pottery centre. An unpublished seminar paper. Nnamdi Azikiwe University.

Yanagi, S. (1978). "Introduction to Hamadas exhibition. (in B. Leach). Hamada Potter, Tokyo, Kodansha International. 